\title{
Erick Falc'her-Poyroux, Histoire sociale de la musique irlandaise : du dadga au DADGAD
}

Jérémy Tétrault-Farber

\section{OpenEdition}

12 Journals

Édition électronique

URL : https://journals.openedition.org/etudesirlandaises/7373

DOI : 10.4000/etudesirlandaises. 7373

ISSN : 2259-8863

Éditeur

Presses universitaires de Caen

Édition imprimée

Date de publication : 14 novembre 2019

Pagination : 150-151

ISBN : 978-2-84133-945-7

ISSN : 0183-973X

Référence électronique

Jérémy Tétrault-Farber, «Erick Falc'her-Poyroux, Histoire sociale de la musique irlandaise : du dadga au DADGAD », Études irlandaises [En ligne], 44-1 | 2019, mis en ligne le 14 novembre 2019, consulté le 16 novembre 2022. URL : http://journals.openedition.org/etudesirlandaises/7373 ; DOI : https://doi.org/ 10.4000/etudesirlandaises.7373

\section{(ब) $\odot \odot$}

Creative Commons - Attribution - Pas d'Utilisation Commerciale - Partage dans les Mêmes Conditions 4.0 International - CC BY-NC-SA 4.0

https://creativecommons.org/licenses/by-nc-sa/4.0/ 


\section{Erick Falc'her-Poyroux, Histoire sociale de la musique irlandaise: $d u$ dadga au DADGAD, Oxford - New York - Vienne, P. Lang, 2018, 580 p.}

Cet ouvrage décrit l'évolution de la musique irlandaise dans ses contextes sociaux, politiques, culturels et économiques au fil des siècles. Erick Falc'her-Poyroux atteint avec brio son objectif de présenter « une somme résumée des connaissances actuelles en matière de musique irlandaise» (p. xix). Il expose avec rigueur et souci du détail l'impact des aléas de l'histoire de l'Irlande sur la musique qui y était jouée, soulignant tout au long de l'œuvre le thème de l'adaptation de cette musique. L'ouvrage est organisé en chapitres alliant thématiques communes et chevauchements d'époques (prenons, par exemple, chapitre II : «Les traditions musicales populaires, 16001850 », et chapitre III : "À la recherche d'une musique nationale, 1700-1920»). Bien que le caractère strictement thématique du dernier chapitre, «Un univers de musiciens et de danseurs ", déteigne face aux chapitres précédents, la structure du livre est néanmoins particulièrement bien choisie, puisqu'elle permet un étalement ordonné de connaissances tirées d'un éventail prodigieux de sources en plusieurs langues. L'auteur aborde également avec délicatesse et précision des sujets aussi controversés que le «celticisme» de la musique irlandaise, et les enjeux identitaires se rattachant à cette musique jouée de plus en plus hors que son contexte d'origine: l'Irlande rurale.

Dans une œuvre de cette ampleur, il est inévitable que certains sujets soient traités avec plus d'attention que d'autres. Bien que l'auteur aborde la grande cornemuse (Highland bagpipes) à quelques reprises, j'ai trouvé surprenant qu'il n'ait présenté qu'une discussion très sommaire des concours de pipe bands auxquels participent plusieurs groupes irlandais. L'auteur indique effectivement que les All-Ireland Pipe Band Championships (championnats de pipe bands de toute l'Irlande) se tiennent en alternance en Irlande du Nord et en République d'Irlande depuis 1946, mais ne souffle mot sur les concours de grande cornemuse depuis ce temps (p. 277-278). Or, deux pipe bands irlandais - Field Marshal Montgomery, de Lisburn, en Irlande du Nord, et Saint Laurence O'Toole, de Dublin - figurent parmi les meilleurs pipe bands de compétition au monde depuis le début des années 2000. Ces groupes incluent d'ailleurs dans leur répertoire plusieurs pièces traditionnelles irlandaises adaptées pour la grande cornemuse. Notons aussi l'apport important de musiciens natifs d'Irlande et d'Irlande du Nord - tels Ryan Canning, Stephen Creighton, et Steven McWhirter - à l'univers de la grande cornemuse et des pipe bands.

Outre ce détail, certaines affirmations de passage font sourciller. L'auteur affirme qu'il n'existe pas de somme résumée des connaissances en musique irlandaise en français, ni en anglais (p. xix). Bien que ce livre soit le plus récent - et assurément un des plus exhaustifs - à traiter de la musique irlandaise autant en anglais qu'en français, il existe bel et bien des ouvrages que l'on pourrait considérer de telles sommes résumées. L'auteur cite, entre autres, A Short History of Irish Traditional Music, de Gearóid Ó hAllmhuráin, et The Companion to Irish Traditional Music, de Fintan Vallely. Aussi il semble étrange de décrire le XVII e siècle (avec la venue d'Oliver Cromwell) comme le plus cruel qu'ait connu l'Irlande (p. 69). Vu l'impact 
dévastateur de la Grande Famine, le XIX ${ }^{\mathrm{e}}$ siècle mériterait peut-être plus cette appellation. Mais il s'agit là d'une pente glissante qu'il vaut mieux éviter.

Somme toute, il s'agit ici d'un tour de force de la part d'Erick Falc'her-Poyroux. Ce livre intéressera ceux cherchant autant un ouvrage de référence qu'un récit narratif sur l'adaptation de la musique irlandaise au fil du temps. Il mériterait d'être traduit en anglais et d'atteindre ainsi un plus grand public.

Jérémy TÉTRAulT-FARBER

\section{Olivier Coquelin, L'Irlande en révolutions, entre nationalismes et conser- vatismes: une histoire politique et sociale, $18^{e}-20^{e}$ siècles, Paris, Syllepse, 2018, 542 p.}

Dans cet ouvrage, tiré d'une thèse enrichie de multiples travaux entrepris depuis, Olivier Coquelin propose de faire l'étude de ce qui semble être une singularité irlandaise. La décennie révolutionnaire qui s'achève en 1923 a vu émerger les clivages qui dominent encore la vie politique de l'île. Cependant ceux-ci ne se sont pas matérialisés par des différences d'approches sociales ou économiques, cet épisode débouchant sur le renforcement d'une idéologie nationale conservatrice transpartisane. Cette singularité est interrogée au travers d'une histoire politique du temps long qui inscrit sur trois siècles l'étude des desseins socio-économiques de plusieurs générations de nationalistes irlandais. On pourra regretter que ce volume, qui choisit le conservatisme et, en écho, le progressisme comme objets d'étude, ne propose pas d'emblée une mise au point claire sur le cadre donné à ces concepts.

L'ouvrage se divise en deux grandes parties. La première reprend, en trois chapitres, les catégories connues de l'histoire du nationalisme irlandais. On y explore les premières expressions patriotiques, le sectarisme religieux des Defenders est étudié, dont l'alliance avec les Irlandais unis jette les bases d'un nationalisme «autochtone» (p. 78) déjà teinté de conservatisme social. Les conceptions politiques, économiques et sociales des nationalistes constitutionnels et révolutionnaires sont ensuite présentées. La deuxième partie de l'ouvrage, la plus stimulante, donne un écho puissant à la première. L'auteur y mène une réflexion approfondie sur les formes les plus progressistes que le nationalisme irlandais ait produites: les mouvements agraire et ouvrier. Au terme de cette lecture croisée, des explications claires émergent qui permettent d'établir l'équilibre des forces entre progressisme et conservatisme chez les nationalistes toutes tendances confondues.

En premier lieu, l'importance des acteurs politiques et sociaux qui par leurs actions construisent une pensée conservatrice ou en facilitent l'apparition. Prenons par exemple le choix d'un mouvement syndical qui se coupe des aspirations populaires en refusant la violence au cœur de la séquence insurrectionnelle de 1920-1923. Sur ce point, on notera que certaines ruptures chronologiques auraient pu être 